\title{
Changing of the guard? A glance at the surgical representation in the Canadian renal transplantation community
}

\author{
Tom McGregor, MD;' Jennifer Bjazevic, MD;1 Premal Patel, MD;' Joshua Koulack, MD² \\ 'University of Manitoba, Section of Urology, Winnipeg, MB, Canada; '2University of Manitoba, Section of Vascular Surgery, Winnipeg, MB, Canada
}

Cite as: Can Urol Assoc J 2016;10(1-2):E7-11. hittp://dx.doi.org/10.5489/cuai.3256

Published online January 14, 2016.

\section{Abstract}

Introduction: Renal transplant is the gold standard treatment for end-stage renal disease (ESRD), and the prevalence of both ESRD and renal transplant has been steadily increasing over the past decade. However, involvement of urology in renal transplant has been declining. We examine the current state of urology involvement in renal transplant programs across Canada.

Methods: A telephone survey of all surgical transplant centres in Canada was performed. Information regarding the number of transplant surgeons, their individual training background, and their involvement in specific procedures, including open and laparoscopic living donor nephrectomy, deceased donor nephrectomy, and recipient renal transplant were collected.

Results: There are 59 Canadian transplant surgeons, including 27 (46\%) who completed a urology residency and 32 (54\%) with a general surgery background. With regards to procedures performed, 58 (98\%) perform recipient renal transplant surgery, 36 (61\%) perform laparoscopic donor nephrectomy, and 17 (29\%) perform open donor nephrectomy. There was no significant difference in the number of surgeons that perform renal recipient surgery, laparoscopic or open donor nephrectomies, and deceased donor nephrectomies between surgeons of the two different training backgrounds.

Conclusions: The role of urology in Canadian renal transplant has declined significantly over the past decade. Given the medical and surgical complexity of renal transplant, along with the growing need for renal transplants, a multidisciplinary team approach is imperative. Strong urology involvement with the transplant team is crucial for optimal care of these complex patients.

\section{Introduction}

Renal transplantation remains the gold standard treatment for end-stage renal disease (ESRD) worldwide, offering improved survival and quality of life for transplant recipients. ${ }^{1}$ Here in Canada, a total of 2367 renal transplant surger- ies were performed in 2013. ${ }^{1}$ The incidence of ESRD, and number of renal transplants performed, has been steadily increasing in Canada since 2003, demonstrating the need for well-trained transplant surgeons. ${ }^{1}$ Naturally, renal surgery is second nature to the urologist, and historically all aspects of renal transplant surgery were overseen and performed by urologic surgeons. ${ }^{2,3}$ More recently, there has been a trend towards decreased involvement of urology in all aspects of the renal transplantation process, including the recipient transplant, donor nephrectomy, and the medical management of the recipient. ${ }^{3-6}$ However, limited data currently exists regarding the current environment of renal transplant in Canada. To gain a better idea of the current involvement of urology in the Canadian transplant arena, we performed a poll of all Canadian transplant programs to determine what surgical subspecialties were performing the transplant surgeries and to see if their involvement varied between the various components of the transplant process.

\section{Methods}

Following approval from the University of Manitoba ethics review board, we performed a poll via telephone of all surgical transplant centres in Canada. The number of transplant surgeons at each centre was recorded, along with their residency and fellowship training background. Details regarding their involvement in the various aspects of the transplant process were also queried; specifically, their involvement in recipient surgery, laparoscopic and open living donor nephrectomy, and cadaveric organ retrieval. Statistics regarding the incidence and prevalence of ESRD and renal transplants were provided from the Canadian Institute for Health Information. ${ }^{1}$ Descriptive statistics and Fisher's exact test were used to analyze the responses and demonstrate correlations. 


\section{Results}

\section{ESRD in Canada}

In 2013, there were 41931 Canadians living with ESRD, an increase of $35 \%$ since 2004 (Table 1). ${ }^{1}$ Diabetes continues to be the most frequent primary cause for ESRD in Canada, accounting for $36 \%$ of cases. ${ }^{1}$ A total of 1291 renal transplants were performed in Canada in 2013, including both living and deceased donor transplants. ${ }^{1}$ Along with the prevalence of ESRD, the number of renal transplants has also been steadily rising since 2004, with an increase of $34.1 \%$ and $26.5 \%$ in the number of deceased and living donor transplants performed, respectively (Tables 2 and 3).

\section{Transplant surgeons in Canada}

There are 18 academic hospitals in Canada where renal transplants are performed and in which 59 surgeons were found to perform renal transplant surgery. Of these physicians, 27 (46\%) completed a urology residency, with the remainder having completed a residency in general surgery $(n=32,54 \%$; Table 4). Of these surgeons, 38 (64\%) completed a transplant fellowship. With regards to procedures performed, 58 (98\%) perform recipient renal transplant surgery, 36 (61\%) perform laparoscopic donor nephrectomies, and 17 (29\%) perform open donor nephrectomies (Table 4). An overwhelming majority of transplant surgeons $(n=58$, 98\%) were male. When looking at regional differences, a significant portion of transplant surgeons within Eastern Canada had completed general surgery residency $(n=18 / 21,86 \%)$ compared with a majority of urologists performing transplantation surgery in Ontario $(n=15 / 21,71 \%)$, and roughly equivalent numbers of urologists and general surgeons performing transplant in Western Canada (Table 4).

\section{Surgical practices of general surgery-trained renal transplant surgeons}

When looking specifically at transplant surgeons who completed their general surgery residency $(n=32), 24(75 \%)$

\begin{tabular}{lccccc}
\hline \multicolumn{6}{l}{ Table 1. Incidence of ESRD in patients by region, Canada } \\
\hline Region & & $\mathbf{2 0 0 4}$ & $\mathbf{2 0 0 7}$ & $\mathbf{2 0 1 0}$ & $\mathbf{2 0 1 3}$ \\
\hline \multirow{2}{*}{ Western } & $\mathrm{n}$ & 1552 & 1688 & 1696 & 1780 \\
& RPMP & 687.7 & 716.6 & 686.6 & 593.4 \\
\multirow{2}{*}{ Ontario } & $\mathrm{n}$ & 2211 & 2363 & 2495 & 2797 \\
& RPMP & 178.4 & 184.7 & 188.6 & 206.6 \\
\multirow{2}{*}{ Eastern } & $\mathrm{n}$ & 1444 & 1463 & 1513 & 756 \\
& RPMP & 713.2 & 647.6 & 748.8 & 461.6 \\
\multirow{2}{*}{ Canada } & $\mathrm{n}$ & 5207 & 5514 & 5704 & 5333 \\
& RPMP & 163.0 & 167.4 & 167.1 & 151.7 \\
\hline ESRD: end-stage renal disease; RPMP: rate per million population.
\end{tabular}

completed a fellowship in transplant, six (19\%) completed a vascular surgery fellowship, and the remainder (6\%) completed an unrelated fellowship. With regards to operative procedures, 31 (97\%) perform recipient renal transplant surgery, 16 (50\%) perform laparoscopic donor nephrectomies, 8 (25\%) perform open donor nephrectomies, and 25 (78\%) perform deceased donor nephrectomies (Fig. 1).

\section{Surgical practices of urology-trained renal transplant surgeons}

When looking at transplant surgeons who completed their urology residency $(n=27), 15(56 \%)$ completed a fellowship in transplantation, five (19\%) in endourology, three $(11 \%)$ in pediatrics, and the remainder (15\%) completed an alternative fellowship or did not pursue fellowship training. With regards to operative procedures, $27(100 \%)$ perform recipient renal transplant surgery, 20 (74\%) perform laparoscopic donor nephrectomies, nine (33\%) perform open donor nephrectomies, and 15 (56\%) perform deceased donor nephrectomies (Fig. 2).

\section{Comparison between urology- and general surgery-trained renal transplant surgeons}

When comparing transplant surgeons with a general surgery background to those with a urology background, there was no difference in the proportion of those performing recipient surgery, open donor nephrectomies, and deceased donor nephrectomies. However, although not statistically significant, there was a trend towards more urologists performing laparoscopic donor nephrectomies $(p=0.0681)$ (Table 5). With regards to fellowship training, there were a greater proportion of general surgeons (75\%) who completed a transplant fellowship as compared to urologists (56\%), although this was not statistically significant.

\section{Discussion}

Urology grandfathered the introduction of renal transplantation, with the first renal transplant being conducted in 1954. ${ }^{2}$ Historically, renal transplant surgery was primarily conducted by urologists, given that it clearly fell within the purview of renal surgery. ${ }^{3,4}$ However, in more modern times, with the increased complexity and specialization of

\begin{tabular}{|c|c|c|c|c|}
\hline Region & 2004 & 2007 & 2010 & 2013 \\
\hline Western & 150 & 180 & 196 & 213 \\
\hline Ontario & 208 & 291 & 308 & 303 \\
\hline Eastern & 231 & 256 & 221 & 274 \\
\hline Canada & 589 & 727 & 725 & 790 \\
\hline
\end{tabular}




\begin{tabular}{|c|c|c|c|c|}
\hline Region & 2004 & 2007 & 2010 & 2013 \\
\hline Western & 159 & 188 & 178 & 210 \\
\hline Ontario & 157 & 199 & 208 & 200 \\
\hline Eastern & 61 & 71 & 80 & 67 \\
\hline Canada & 377 & 458 & 466 & 477 \\
\hline
\end{tabular}

the transplant field, the role of urology in renal transplant has been declining. ${ }^{3}$ This diminishing role of urology in renal transplant has been well-documented in the U.S., ${ }^{4,5},-9$ Anecdotally, it has been felt that a similar trend is being followed in Canada; however, this has yet to be demonstrated. This study aimed to characterize the training background and surgical practices of renal transplant surgeons across Canada.

We found that $46 \%$ of renal transplant surgeons had completed a urology residency, whereas, 54\% came from a general surgery background, representing a fairly equal split between the two training backgrounds. This represents a dramatic decline in the involvement of urology in renal transplant since its inception, when it was almost entirely performed by urology. This mirrors the trend that has been well-demonstrated in the U.S. ${ }^{9}$

The first published evidence of this trend dates back to 1986, when Novick et al described a diminishing role of urology in various transplant procedures, as well decreased resident exposure to renal transplant. ${ }^{4}$ However, this movement likely began at least a decade prior, given the time between physician training and clinical practice. Following this, Flechner et al quantified the composition of transplant programs across Canada and the U.S. in 1997, and further demonstrated progression of this pattern. ${ }^{8}$ Their study clearly showed that general surgery had gained domination of renal transplant in the U.S., with the vast majority of renal transplant programs, $71.5 \%$, being directed by the department of general surgery. ${ }^{8}$ In contrast, only $11.4 \%$ of programs were directed by urology and $10.5 \%$ were jointly directed. The remaining $6.6 \%$ is unknown. ${ }^{8}$ The situation was less dra- matic in Canada, where $30.7 \%$ of renal transplant programs were directed by urology. ${ }^{8}$

When examining the American data by surgical procedure, Flechner et al found that urology was only involved in a minority of the cadaveric donor nephrectomies and renal recipient transplants, with urology only being primarily responsible for $27 \%$ and $23 \%$ of the procedures, respectively. ${ }^{8}$ Despite this, urologists in the U.S. at the time were still primarily involved in the majority, $63 \%$, of living donor nephrectomies. ${ }^{8}$ However, when this was re-examined in 2008 by Wright et al, the trend towards decreasing urological involvement had progressed, with now only $32 \%$ of living donor nephrectomies being primarily performed by urology-trained surgeons. ${ }^{9}$ This represented a rapid decline in urological involvement of approximately $30 \%$ over a 10-year span..$^{9,10}$

Our results show that the involvement of both general surgery and urology-trained surgeons is approximately equivalent for each of the specific renal transplant procedures. Specifically, for the recipient surgery, general surgery was primarily involved in $53.4 \%$ of these procedures. This demonstrates an incredibly dramatic decline from the data Flechner reported in 1997, where urology was primarily responsible for $92 \%$ of renal recipient transplants in Canada. ${ }^{8}$

A strikingly similar trend is observed for both open and laparoscopic living donor nephrectomies. Again, our results demonstrate approximately equal participation of both general surgery and urology for the completion of these procedures. More precisely, urology was primarily responsible for $55.6 \%$ of laparoscopic donor nephrectomies and 52.9\% of open donor nephrectomies. This is in stark comparison to 1997 , when $100 \%$ of living donor nephrectomies were performed primarily by urology. ${ }^{9}$ This trend is also consistent for cadaveric donor nephrectomies, where previously these were performed entirely by urology; however, our recent data now shows that $61.0 \%$ of cadaveric retrievals are primarily performed by general surgeons. ${ }^{9}$

The declining involvement of urology in renal transplant has also translated into affecting urology residency training.

Table 4. Overview of all renal transplant surgeons across Canada

\begin{tabular}{|c|c|c|c|c|c|c|c|}
\hline Region & $\begin{array}{c}\text { Gender } \\
\text { M:F }\end{array}$ & Recipient surgery & LDN & ODN & DDN & $\begin{array}{c}\text { Residency } \\
\text { GS = General surgery } \\
\text { U = Urology }\end{array}$ & $\begin{array}{l}\text { Transplant } \\
\text { fellowship }\end{array}$ \\
\hline \multirow{2}{*}{ Western } & \multirow{2}{*}{ 17:0 } & Yes - 17 & Yes - 12 & Yes - 8 & Yes - 14 & $\mathrm{GS}-8$ & Yes - 11 \\
\hline & & No - 0 & No - 5 & No -9 & No - 3 & $U-9$ & No - 6 \\
\hline \multirow{2}{*}{ Ontario } & \multirow{2}{*}{ 21:0 } & Yes - 20 & Yes - 14 & Yes - 4 & Yes -9 & GS - 6 & Yes - 11 \\
\hline & & No - 1 & No -7 & No - 17 & No -12 & $U-15$ & No - 10 \\
\hline \multirow{2}{*}{ Eastern } & \multirow{2}{*}{$20: 1$} & Yes - 21 & Yes - 10 & Yes -5 & Yes - 17 & GS - 18 & Yes - 17 \\
\hline & & No - 0 & No - 11 & No -16 & No - 4 & $U-3$ & No - 4 \\
\hline \multirow{2}{*}{ Canada } & \multirow{2}{*}{$58: 1$} & Yes - 58 & Yes - 36 & Yes - 17 & Yes -40 & GS - 32 & Yes - 39 \\
\hline & & No - 1 & No -23 & No -42 & No -19 & $U-27$ & No -20 \\
\hline
\end{tabular}




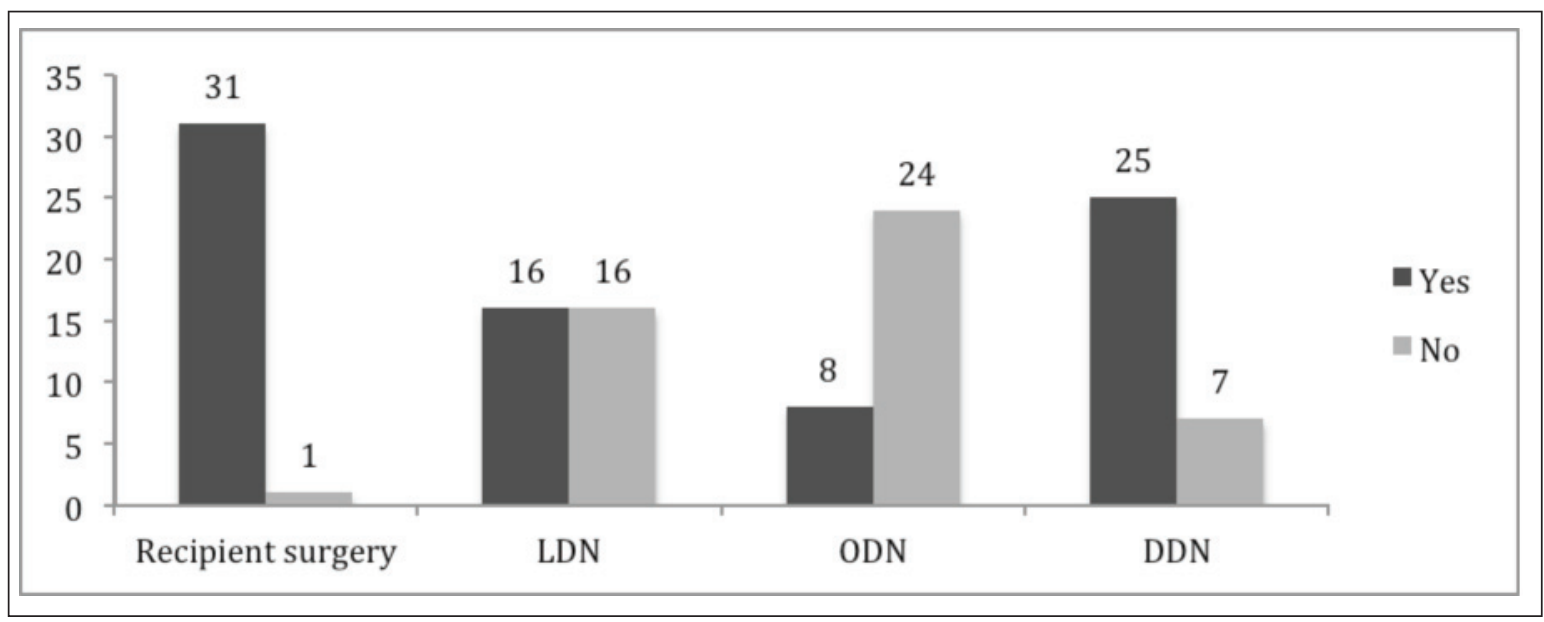

Fig. 1. Procedures performed by transplant surgeons who completed their general surgery residency. DDN: deceased donor nephrectomy; LDN: laparoscopic donor nephrectomy; ODN: open donor nephrectomy.

It has been demonstrated that the number of Canadian urology residency programs that offer exposure to renal transplant, has dropped significantly from 100\% in 1997 to $77 \%$ in 2014. ${ }^{9,11}$ This declining role of urology in renal transplant is likely multifactorial. Certainly, diminished opportunities for resident exposure and training in renal transplant have played an important role. ${ }^{9,11}$ Trainees report that a lack of early exposure to transplant was their main reason for not pursuing a career in this field. ${ }^{12}$ In addition, there has been a de-emphasis of training in vascular surgery during urology residency, which may also be a factor. ${ }^{3}$ Furthermore, changes in the field of urology, to focus more on generalist and office urology practices have likely also contributed to a declining interest in renal transplant. ${ }^{6}$ However, the biggest factor has been the dramatic medical and surgical advances in the transplant field in recent years. This has greatly increased the complexity of the transplant field and necessitated further training of urologists after residency to become specialized in transplant. ${ }^{3}$ As a result, multi-organ (in comparison to kidney-only) transplant fellowships predominate and these are primarily completed by physicians who have a general surgery training background. This has served to greatly increase the involvement of vascular and general surgery in renal transplant and, thereby, dilute the presence of urology. 3,9

Given the recent substantial technical and medical advances in the field of transplantation, a multidisciplinary team approach to these complex patients is now advocated as the standard of care. ${ }^{13,14}$ The interdisciplinary approach can have a dramatic impact on patient outcomes and has been demonstrated to increase the number of living donor transplants, thereby reduce waiting times, as well as decreasing infection rates, episodes of acute rejection, and cold ischemic time. ${ }^{13,15}$ These teams often include a urologist, a

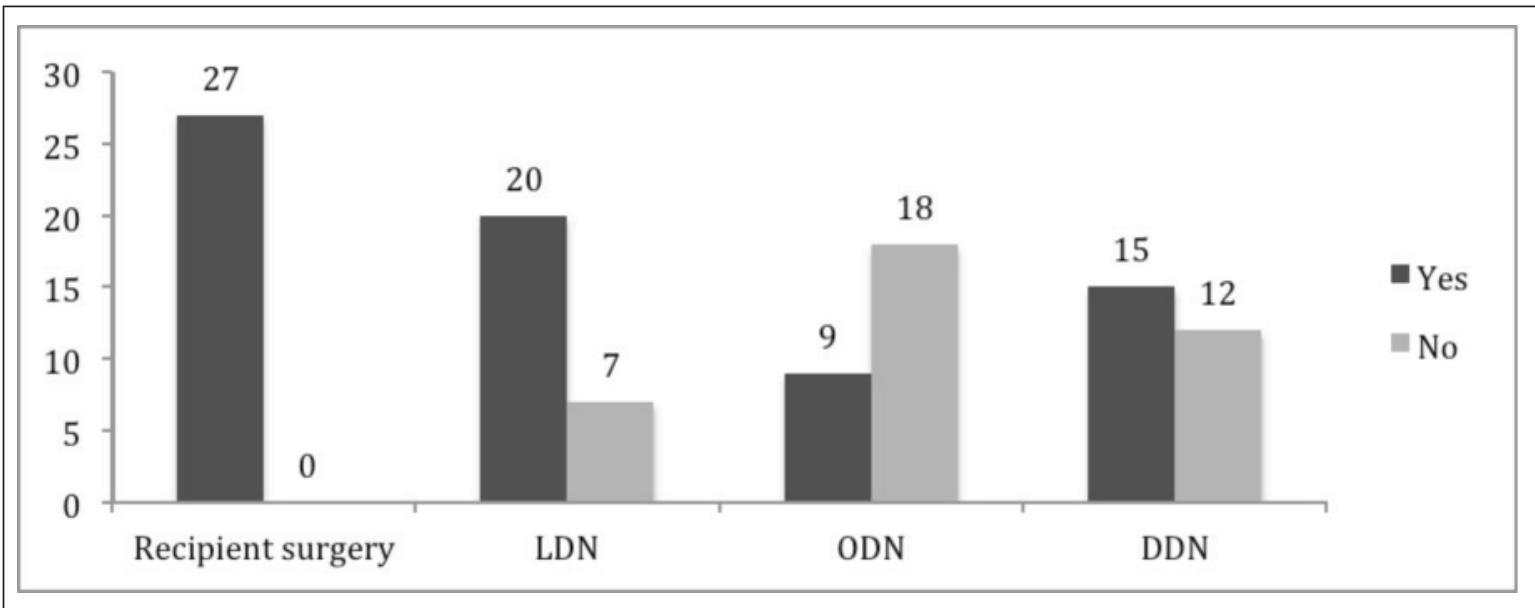

Fig. 2. Procedures performed by transplant surgeons who completed their urology residency. DDN: deceased donor nephrectomy; LDN: laparoscopic donor nephrectomy; ODN: open donor nephrectomy. 


\begin{tabular}{|c|c|c|c|c|}
\hline & & $\begin{array}{l}\text { General } \\
\text { surgery }\end{array}$ & Urology & $p$ value \\
\hline \multirow{2}{*}{$\begin{array}{l}\text { Recipient } \\
\text { surgery }\end{array}$} & Yes & 31 & 27 & \multirow[t]{2}{*}{1.000} \\
\hline & No & 1 & 0 & \\
\hline \multirow{2}{*}{ LDN } & Yes & 16 & 20 & \multirow[t]{2}{*}{0.0681} \\
\hline & No & 16 & 7 & \\
\hline \multirow{2}{*}{ ODN } & Yes & 8 & 9 & \multirow[t]{2}{*}{0.5692} \\
\hline & No & 24 & 18 & \\
\hline \multirow{2}{*}{ DDN } & Yes & 25 & 15 & \multirow[t]{2}{*}{0.0940} \\
\hline & No & 7 & 12 & \\
\hline \multirow{2}{*}{ Fellowship } & Transplant & 24 & 15 & \multirow[t]{2}{*}{0.1682} \\
\hline & Other & 8 & 12 & \\
\hline
\end{tabular}

DDN: deceased donor nephrectomy; LDN: laparoscopic donor nephrectomy; ODN: open donor nephrectomy.

vascular or general surgeon, a nephrologist, and a transplant nurse or coordinator. ${ }^{13}$ The Royal College of Surgeons of England has advocated the involvement of a urologist with a strong commitment to renal transplant on the transplant team. ${ }^{14}$ In addition, there is growing evidence that surgical specialization results in improved patient outcomes, especially following high-risk surgical procedures, further justifying the instrumental role of urology on the transplant team. ${ }^{16,17}$ However, our data demonstrate that less than half, $41.6 \%$, of transplant programs across Canada have a multidisciplinary team including both urologists and general surgeons.

Urologists remain a vital member of the transplant team given the inherent genitourinary nature of renal transplant. Preoperatively, urology is involved in the workup and management of urologic conditions that are common in patients with ESRD. Furthermore, postoperatively, renal transplant recipients are often at increased risk of benign prostatic hypertrophy $(\mathrm{BPH})$, voiding dysfunction, and a number of other urological allograft-related complications. ${ }^{3}$ In fact, ureteric strictures, typically managed by a urologist, are the most common complication following renal transplant. ${ }^{18}$

Given the medical and surgical complexity of renal transplant, along with the growing need for renal transplants in the Canadian population, a multidisciplinary team approach is imperative. Strong urology involvement with the transplant team is crucial for the optimal care of these complex patients.

\section{Conclusion}

Our study characterizes the surgical makeup and training background of transplant surgeons in Canada. Although the declining trend of urologic involvement in the various aspects of renal transplant is not as dramatic as has been shown in the U.S., our results do support a trend towards a declining role of urology in Canadian transplant programs.

Competing interests: The authors declare no competing financial or personal interests.

This paper has been peer-reviewed.

\section{References}

1. Canadian Institute for Health Information. Canadian Organ Replacement Register Annual Report: Treatment of end-stage organ failure in Canada, 2004 to 2013. Ottawa, ON: CIHI:2015. hittps://secure.cihi.ca/ free_products/2015_CORR_AnnualReport_ENweb.pdf. Accessed Dec. 15, 2015.

2. Merill JP, Murray JE, Harrison JH, et al. Successful homotransplantations of the human kidney between identical twins. JAMA 1956;67:160:277-82. http://dx.doi.org/10.1001/jama.1956.02960390027008

3. Sackett D, Singh P, Lallas CD. Urological involvement in renal transplantation. Int J Urol 201 1;18:185-93. http://dx.doi.org/10.1111/j.1442-2042.2010.02707.x

4. Novick $A C$, Flechner, $S$. The integration of clinical renal transplantation into urology residency training. J Urol 1988; 139:568-9.

5. Navarrete RV. RE: The current level of involvement of urological trainees and faculty in clinical kidney transplantation in the U.S. and Canada. J Urol 1998;159:513. http://dx.doi.org/10.1016/S0022$5347(01) 63973-9$

6. Besarani D, Cranston D. Renal transplantation and manpower issues. BJU Int 2005;96:231-6. http:// dx.doi.org/10.1111/i.1464-410X.2005.05608.x

7. Duchene DA, Moinzaden A, Gill IS, et al. Survey of residency training in laparoscopic and robotic surgery. J Urol 2006;176:2158-67. http://dx.doi.org/10.1016/i.juro.2006.07.035

8. Flechner SM, Novick AC. The current level of involvement of urological trainees and faculty in clinical kidney transplantation in the U.S. and Canada. J Urol 1997;157:1223-5. http://dx.doi.org/10.1016/ S0022-5347(01)64928-0

9. Wright AD, Will TA, Holt DR, et al. Laparoscopic living donor nephrectomy: A look at current trends and practice patterns at major transplant centers across the U.S. J Urol 2008;179:1488-92. httr://dx.doi. org/10.1016/i.juro.2007.11.066

10. Peters PC. The place of renal transplantation in urology. Urol Clin N Amer 1983;10:369-70.

11. Biazevic J, McGregor TM. Current perspective of urology involvement in renal transplantation: A survey of Canadian senior residents. Urol Pract 2015;2:1-6. http://dx.doi.org/10.1016/i.urpr.2015.03.001

12. Morris-Stiff GJ, Benson S, Casey J, et al. Transplant surgeons in training: Is anybody out there? Ann R Coll Surg Engl 1999;81:191-4.

13. Fonouni $H$, Golriz $M$, Mehrabi A, et al. The role an interdisciplinary transplant team on living donation kidney transplantation program. Transplant Proc 2010;42:137-40. http://dx.doi.org/10.1016/i. transproceed.2009.12.038

14. Morris P. Report of the working part to review organ transplantation. Ann R Coll Surg Engl 1999;81:128.

15. Taber DJ, Pilch NA, McGillicuddy JW, et al. Improved patient safety and outcomes with a comprehensive interdisciplinary improvement initiative in kidney transplant recipients. Am J Med Qual 2013;28:103-12. http://dx.doi.org/10.1177/1062860612450309

16. Goodney PP, Lucas FL, Stukel TA, et al. Surgeon speciality and operative mortality with lung resection. Ann Surg 2005;241:179-84.

17. Hannan EL, Popp AJ, Feustel P, et al. Association of surgical speciality and processes of care with patient outcomes for carotid endarterectomy. Stroke 2001;32:2890-7. http://dx.doi.org/10.1161/ hs 1201.099637

18. Kroczak T, Koulack J, McGregor T. Management of complicated ureteric stricture post-renal transplant: Case series utilizing pyelovesicostomy with Boari flap. Transplant Proc 2015;47:1850-3. http://dx.doi. org/10.1016/i.transproceed.2015.02.020

Correspondence: Dr. Thomas McGregor, Department of Surgery, Section of Urology, University of Manitoba, Winnipeg, MB, Canada; tom8mc@hotmail.com 